\title{
Molecular Characterization of a Pathogen-Inducible Bidirectional Promoter from Hot Pepper (Capsicum annuum)
}

\author{
Solhee In, ${ }^{1,2}$ Hyun-Ah Lee, ${ }^{3}$ Jongchan Woo, ${ }^{2,4}$ Eunsook Park, ${ }^{2,4}$ and Doil Choi ${ }^{1,2,+}$ \\ ${ }^{1}$ Department of Plant Science, College of Agriculture and Life Sciences, Seoul National University, Seoul 08826, Republic of \\ Korea \\ ${ }^{2}$ Plant Immunity Research Center, Seoul National University, Seoul 08826, Republic of Korea \\ ${ }^{3}$ Division of Eco-Friendly Horticulture, Yonam College, Cheonan 31005, Republic of Korea \\ ${ }^{4}$ Department of Molecular Biology, University of Wyoming, Laramie, WY 82071, U.S.A.
}

Accepted 7 August 2020.

In hot pepper, the sesquiterpene phytoalexin capsidiol is catalyzed by the two final-step enzymes, a sesquiterpene cyclase (EAS) and a hydroxylase (EAH), which are genetically linked and present as head-to-head orientation in the genome. Transcriptomic analysis revealed that a subset of $E A S$ and $E A H$ is highly induced following pathogen infection, suggesting the coregulation of $E A S$ and $E A H$ by a potential bidirectional activity of the promoter ( $\mathrm{pCaD})$. A series of the nested deletions of $\mathrm{pCaD}$ in both directions verified the bidirectional promoter activity of the pCaD. Promoter deletion analysis revealed that the 226 bp of the adjacent promoter region of $E A S$ and GCCbox in $E A H$ orientation were determined as critical regulatory elements for the induction of each gene. Based on promoter analyses, we generated a set of synthetic promoters to maximize reporter gene expression within the minimal length of the promoter in both directions. We found that the reporter gene expression was remarkably induced upon infection with $P$ hytophthora capsici, Phytophthora infestans, and bacterial pathogen Pseudomonas syringae pv. tomato DC3000 but not with necrotrophic fungi Botrytis cinerea. Our results confirmed the bidirectional activity of the $\mathrm{pCaD}$ located between the head-tohead oriented phytoalexin biosynthetic genes in hot pepper. Furthermore, the synthetic promoter modified in $\mathrm{pCaD}$ could be a potential tool for pathogen-inducible expression of target genes for developing disease-resistant crops.

Keywords: disease resistance, hot pepper, pathogen-inducible promoter, phytoalexin, transient expression

Crop loss caused by biotic stress is one of the most serious problems of sustainable crop production (Carvalho 2017;

\section{${ }^{\dagger}$ Corresponding author: D. Choi; doil@snu.ac.kr}

Funding: This work was supported by grants from the Korea Research Foundation funded by the Ministry of Science and ICT of the Korean Government (numbers 2018 R1A5A1023599 and 2018 R1A2A1A05019892).

*The $\boldsymbol{e}$-Xtra logo stands for "electronic extra" and indicates there are supplementary materials published online.

The author(s) declare no conflict of interest. Copyright $\odot 2020$ The Author(s). This is an open access article
distributed under the CC BY-NC-ND 4.0 International license. distributed under the CC BY-NC-ND 4.0 International license.
Chakraborty and Newton 2011; Ficke et al. 2018; Nalley et al. 2016). Application of fungicides and pesticides to prevent pathogen infection causes unexpected outcomes, such as a deleterious effect on soil microorganisms and agricultural poisoning (Baćmaga et al. 2016; Wyszkowska and Kucharski 2004). To minimize the loss by pathogens for the maximal crop yield, various approaches were executed to identify plant defense-related genes and to introduce those genes for ectopic expression in the crops (Alexander et al. 1993; Brogue et al. 1991; Truong et al. 2012; Zhao et al. 2005; Zhu et al. 2012). Among these trials, a series of inducible or constitutive promoters have been explored to express target genes to obtain disease-resistant crops (Boni et al. 2018; Cao et al. 1998; Chen and Chen 2002; Li et al. 2004; Yamamizo et al. 2006). However, despite experimental usefulness, expression of the genes by constitutive promoters resulted in undesirable features, including morphological changes by the excessive expression of the introduced gene (Chen and Chen 2002; Fitzgerald et al. 2004; Li et al. 2004; Yi and Richards 2007). To overcome the defects of constitutive promoters, inducible defense systems have been paid considerable attention to identify appropriate promoters for inducible gene expression in response to pathogen infection (Keller et al. 1999; Xu et al. 2017).

Plants have evolved an array of defense components against pathogen attack, encompassing physical barriers, antimicrobial compounds, and induced immune responses (Ham et al. 2007; Heath 2000; Lee et al. 2017; Nürnberger and Lipka 2005). Recognition of pathogen-associated molecular patterns or secreted effector proteins from pathogens results in defense responses such as activation of a mitogen-activated protein kinase cascade, callose deposition for reinforcement of physical barrier of host cells, the release of reactive oxygen species, induction of defense-related phytoalexins and hormone biosynthesis, and often resulted in hypersensitive response (Boller and Felix 2009; Kamoun et al. 1999; Robert-Seilaniantz et al. 2007; Vleeshouwers et al. 2000).

Phytoalexins are low-molecular weight antimicrobial compounds that de novo synthesized upon pathogen recognition or biotic stress (Choi et al. 1992, 1994; Kuc 1995; Li et al. 2015; Yang et al. 2017). Phytoalexins are categorized into several subclasses of secondary metabolites, such as phenolics, alkaloids, or terpenes, and are synthesized in plant species-specific manners (Bednarek et al. 2011; Gust et al. 2007; Piasecka et al. 2015; Stoessl et al. 1972). 
Capsidiol, a bicyclic sesquiterpene, possesses antifungal and antimicrobial activity against fungal and oomycete pathogens (Giannakopoulou et al. 2014; Stoessl et al. 1972). It is a typical phytoalexin of Nicotiana and Capsicum genera and catabolized by two key enzymes, EAS (5-epi-aristolochene synthase) and EAH (5-epi-aristolochene hydroxylase) in response to elicitor treatments and pathogen infections (Bailey et al. 1976; Li et al. 2015; Ralston et al. 2001; Starks et al. 1997; Stoessl et al. 1972; Vögeli and Chappell 1988). EAS is the sesquiterpene cyclase that converts farnesyl diphosphate to 5-epi-aristolochene and EAH hydroxylate 5-epi-aristolochene to capsidiol (Ralston et al. 2001; Whitehead et al. 1989).

Recently, capsidiol has been reported to play a critical role in defense against nonadapted pathogen $P$. infestans in hot pepper (Lee et al. 2017). The expression of $E A S$ and $E A H$ was highly induced in Capsicum annuum cv. CM334 following infection with an adapted pathogen, $P$. capsici, as well as a nonadapted pathogen, $P$. infestans (Lee et al. 2017). Furthermore, reduction of the capsidiol by EAS gene silencing allows the colonization of $P$. infestans in its nonadapted host pepper, indicating that capsidiol may play a pivotal role in the nonhost resistance of pepper plants against $P$. infestans (Lee et al. 2017).

According to genomic sequence analysis, $29 E A S$ and 28 $E A H$ orthologs are found in the $C$. annuum cv. CM334 genome and subsets of $E A S$ and $E A H$ are located in a head-to-head manner in chromosomes, suggesting the transcriptional coregulation by putative bidirectional promoters.

In this study, we further analyzed the bidirectional inducible property of capsidiol biosynthetic genes. The intergenic region of the $E A S / E A H$ gene pair located in chromosome 2 was selected as a putative promoter region named $\mathrm{pCaD}$. Based on in silico prediction of cis-acting elements, we attended to ethylene-responsive elements (GCC-box) and W-box elements that are the binding sites of WRKY transcription factors, because ethylene-responsive factors (ERFs) and WRKYs are well-characterized plant defense-related transcription factors (Lu et al. 2013; Seo et al. 2015; Ülker and Somssich, 2004). Based on one GCC-box and four W-box sequences, we generated a series of deletion promoters with two reporter genes to identify the regions that required for the bidirectional inducible property of $\mathrm{pCaD}$. In addition, a minimal synthetic promoter, named pMin, from $\mathrm{pCaD}$ was constructed to confirm enhanced reporter gene expression following pathogen inoculation. Since there are only a few cases of the characterization of bidirectional promoters in plants and their application for enhancing crop resistance (Arnaiz et al. 2019; Shin et al. 2003), our study could provide more efficient pathogen-inducible promoters in response to biotic stresses that are of benefit for developing disease-resistant crops expressing a candidate gene (or genes) of interest driven by the versatile promoters.

\section{RESULTS}

\section{Inoculation of $\boldsymbol{P}$. capsici or $\boldsymbol{P}$. infestans significantly enhanced the expression of reporter genes fused to pCaD bidirectionally.}

Compared with tomato, the genomic regions between the genes that have a syntenic relationship specifically have been expanded in hot pepper and one of the capsidiol biosynthetic gene pairs, CA02g09520 (EAS) and CA02g09530 (EAH), is highly induced following infection of $P$. capsici and $P$. infestans in C. annuum 'CM334' (Lee et al. 2017). Intriguingly, $E A S$ and $E A H$ are arrayed in a head-to-head orientation in the genome (Fig. 1A), suggesting that the intergenic promoter region ( $1,156 \mathrm{bp}$ ) between $E A S$ and $E A H$ (named as pCaD) has a potential to be a bidirectional promoter induced by infection of $P$. capsici and $P$. infestans. To examine a dual promoter activity of $\mathrm{pCaD}, \mathrm{pCaD}$ was fused to two reporter genes, super humanized Renilla luciferase ( $s h R L U C$ ) (to the direction of $E A H$ transcription, pCaDrev::shRLUC [Woo et al. 2008]) and enhanced green fluorescent protein (EGFP) (to the direction of $E A S$ transcription, pCaD::EGFP) (Fig. 1B). The dual reporter gene cassette (shRLUC::pCaD::EGFP) was transiently expressed in Nicotiana benthamiana leaves by agroinfiltration (Sparkes et al. 2006) and inoculation of $P$. capsici and $P$. infestans was conducted after $24 \mathrm{~h}$ after agroinfiltration. Significantly enhanced expression of EGFP and shRLUC was observed in $\mathrm{pCaD}$ driven construct compare with that of pNos driven construct at 12 and $24 \mathrm{~h}$ postinoculation (hpi) (Fig. 1C and D). This result suggested that $\mathrm{pCaD}$ possesses bidirectional promoter activity with inducible properties against pathogen infection.

Three W-box elements and a GCC-box element in pCaD
differentially regulate the bidirectional promotor activity.

In silico prediction showed that the $\mathrm{pCaD}$ has putative cisacting elements including a GCC-box that ERFs bind to and Wbox elements that were known to be the binding site of WRKY transcription factor (Eulgem et al. 2000; Fujimoto et al. 2000; Ohme-Takagi and Shinshi 1995) (Fig. 1B). In earlier studies, it has been reported that ERFs and WRKYs mediate defense responses in various plant species (Adachi et al. 2015; Jin et al. 2016; Sarris et al. 2015; Song et al. 2019).

To identify the crucial region of $\mathrm{pCaD}$ promoter activity, serial deletion of the $\mathrm{pCaD}$ promoter was performed, based on GCC- and W-box sequences in both directions (Supplementary Fig. S1). pCaD and its deleted promoters were fused to EGFP and $s h R L U C$ reporter genes and were expressed in $N$. benthamiana leaves using agroinfiltration (Figs. 2 and 3). Two days after agroinfiltration, EGFP expression regulated by $\mathrm{pCaD}$ and its deletion promoters showed different activities of each cis element to the pCaD promoter activity (Fig. 2). A complete loss of EGFP fluorescence was observed when the 264-bp promoter region including the fourth W-box (W4) was deleted $\left(\mathrm{pGW}_{123}\right)$. A substantial recovery of EGFP expression by a 226-bp fragment of the $\mathrm{pCaD}$ $\left(\mathrm{GW}_{\text {null }}\right)$ indicates that $226 \mathrm{bp}$ of $\mathrm{pCaD}$ is critical for transcript expression toward the direction of EAS. Interestingly, the deletion of the GCC-box and the second W-box (W2) resulted in an increase of EGFP expression, suggesting that both cis elements might negatively regulate $\mathrm{pCaD}$ activity in $E A S$ transcription.

For the direction of $E A H, s h R L U C$ was fused to $\mathrm{pCaDrev}$ and its deletion series (Fig. 3). Remarkably, the GCC-box is sufficient to recover the full strength of the $\mathrm{pCaDrev}$ promoter activity $\left(\mathrm{pG}_{\text {only }}\right)$. Apparently, the presence of $\mathrm{W} 1$ has an additive effect on shRLUC expression, while $\mathrm{W} 3$ has a negative effect to pCaDrev promoter activity (Fig. 3). Taken together, these results indicate that a 199-bp fragment containing the GCC-box for $E A H$ and a downstream region of $226 \mathrm{bp}$ for $E A S$ are minimal promoters for the pathogen-inducible expression of the head-to-head arrayed phytoalexin biosynthetic genes.

\section{A minimal synthetic promoter drives enhanced reporter gene expression following inoculation of $P$. capsici, $P$. infestans, and Pseudomonas syringae pv. tomato DC3000 but not of the necrotrophic pathogen Botrytis cinerea.}

To identify the minimal region of the promoter that maintains the inducibility by infections with other pathogens and sustains the strength of the promoter activity, five synthetic promoters were constructed in combination with the cis elements (Fig. 4A). EGFP and shRLUC expression driven by synthetic promoters was measured 2 days after agroinfiltration. shRLUC expression driven by synthetic promoters significantly differs depending on the existence of the W-box elements, while the fluorescence intensities of EGFP were elevated significantly by the deletion of the W-boxes (Fig. 4A). 
Among the series of deleted promoters, we chose the shortest synthetic promoter, pMin, to test whether pMin responds to various pathogen infections. At $24 \mathrm{~h}$ after agroinfiltration of dual reporter cassettes driven by $\mathrm{pCaD}$ and $\mathrm{pMin}$ in $N$. benthamiana leaves, inoculation of $P$. capsici, $P$. infestans, Pseudomonas syringae pv. tomato DC3000, and B. cinerea were conducted as described below.

EGFP expression not only was driven by $\mathrm{pCaD}$ but was also driven by pMin and significantly increased after infection of P. capsici, $P$. infestans, and Pseudomonas syringae pv. tomato DC3000 at 12 hpi (Fig. 4B, C, and D). On the other hand, increased shRLUC activity was also detected after pathogen infection except in the case of B. cinerea inoculation (Fig. 4B, C, and D). P. capsici and P. infestans infection cause enhanced
shRLUC expression at $24 \mathrm{hpi}$ (Fig. 4B and C). In the case of Pseudomonas syringae pv. tomato DC3000, shRLUC activity was significantly elevated at 12 hpi (Fig. 4D), while B. cinerea inoculation resulted in significantly lower shRLUC expression in the early infection stage (6 hpi) (Fig. 4E). These results confirmed that not only $\mathrm{pCaD}$ but also pMin have pathogeninducible properties against $P$. capsici, $P$. infestans, and Pseudomonas syringae pv. tomato DC3000 infections.

Pvr4-CC expression driven by $\mathrm{pCaD}$ and pMin elicits stronger cell death than that driven by the $35 \mathrm{~S}$ promoter.

Generating transgenic plants using pathogen-inducible promoters and resistance-related genes can enhance resistance

A

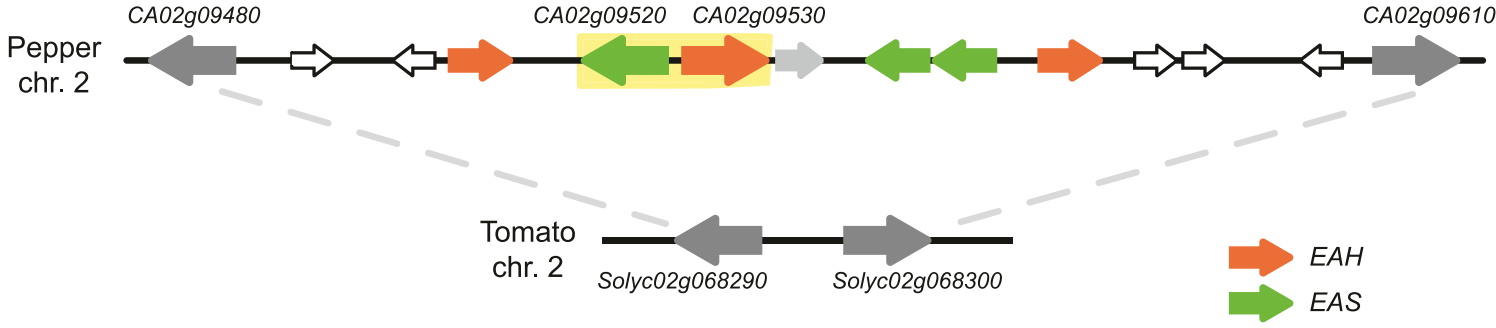

B

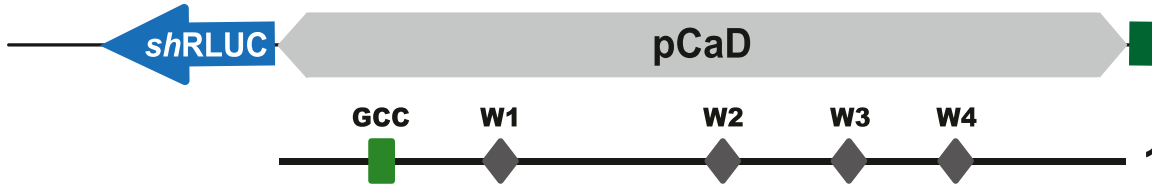

EGFP

1156

C P. capsici

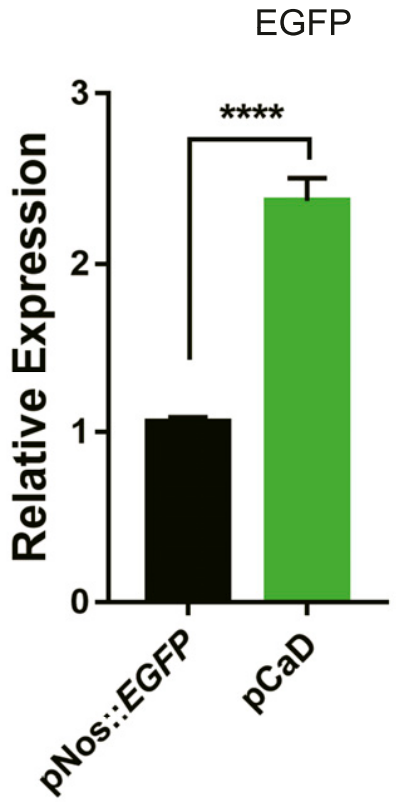

D P. infestans

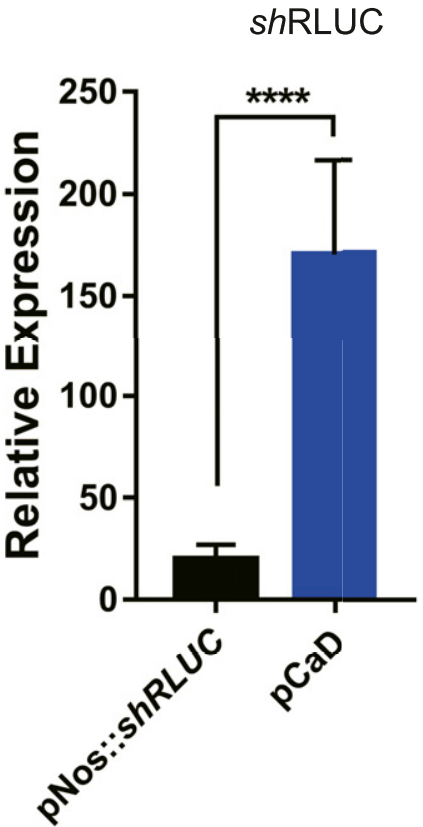

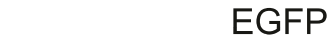

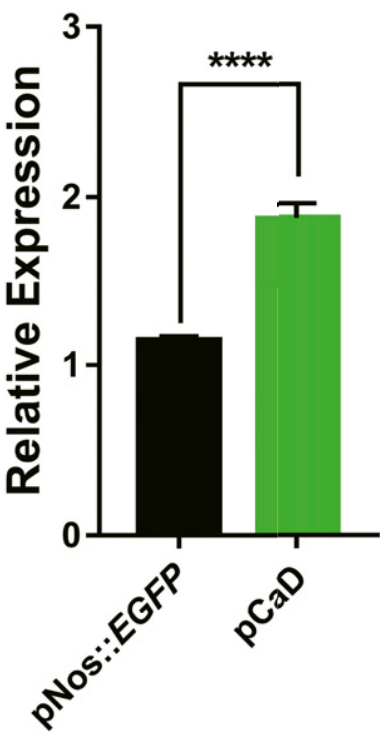

shRLUC

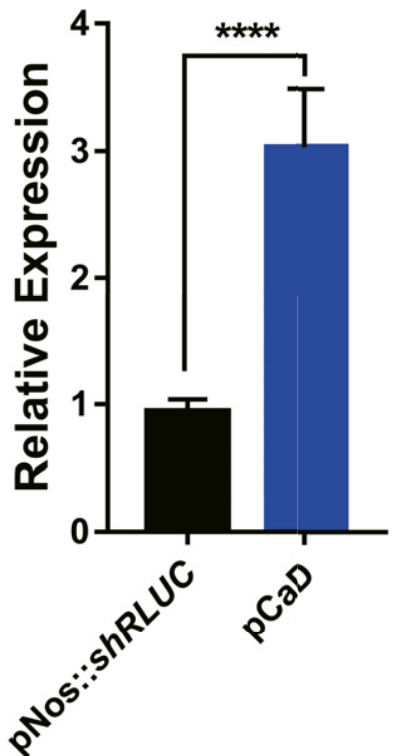

Fig. 1. Intergenic region of $C A 02 g 09530$ and $C A 02 g 09520(\mathrm{pCaD})$ bidirectionally regulates reporter gene expression. A, Location of $C A 02 g 09530$ and CA02g09520 in Capsicum annuum 'CM334' (yellow box). B, Scheme of dual reporter gene cassette. shRLUC and enhanced green fluorescent protein (EGFP) were used to measure the transcriptional activity of pCaD. C, EGFP expression and $\mathbf{D}$, shRLUC activity was detected after Phytophthora capsici and $P$. infestans inoculation. Reporter gene expression driven by the Nos promoter (pNos) was used as a negative control. EGFP expression induced by $P$. capsici was measured at $12 \mathrm{~h}$ after inoculation (hpi) ( $n=64$, error bar, standard error of the mean [SEM]) and shRLUC activity was measured at $24 \mathrm{hpi}(n=40$, error bar, SEM). EGFP and shRLUC expression induced by $P$. infestans was observed at 12 and 24 hpi $(n=64$, error bar, \pm SEM and $n=32$, error bar, \pm SEM, respectively). Relative expressions indicate fold change of EGFP and shRLUC expression compared with mock-treated samples. Significant differences were detected using the Mann-Whitney test. Asterisks $(* * * *)$ indicate $P<0.05$. 
against pathogens by cell death to restrict pathogen spread (Boni et al. 2018; Keller et al. 1999; Yamamizo et al. 2006). Recently, it has been reported that the coiled-coil domain of Pvr4 (Pvr4-CC), including an untranslated region (UTR), can induce cell death under the control of the $35 \mathrm{~S}$ promoter (Kim et al. 2018). To make constructs that induce cell death after pathogen recognition, Pvr4-CC, except for its 5' UTR, was fused to either end of $\mathrm{pCaD}$ and pMin for bidirectional transcription (Fig. 5A; Supplementary Fig. S1B). Pvr4-CC, except for its $5^{\prime}$ UTR, fused to the $35 S$ promoter was used as a positive control, while 10-1-CC, which cannot induce cell death but is included in same subclade with Pvr4, was used as a negative control for cell death upon expression (Lee et al. 2020). Agrobacterium containing each construct was infiltrated into $N$. benthamiana leaves and cell death was observed at 2 days after agroinfiltration.

Enhanced cell death driven by $\mathrm{pCaD}$ and pMin was observed, compared with that driven by the $35 \mathrm{~S}$ promoter in a transient expression assay (Fig. 5B). Cell death intensity was measured by comparing photosynthetic efficiency in each area (Fig. 5C and D). Relative $F v / F m$ ratio was decreased in pCaD::Pvr4-CC and pMin::Pvr4-CC expressed

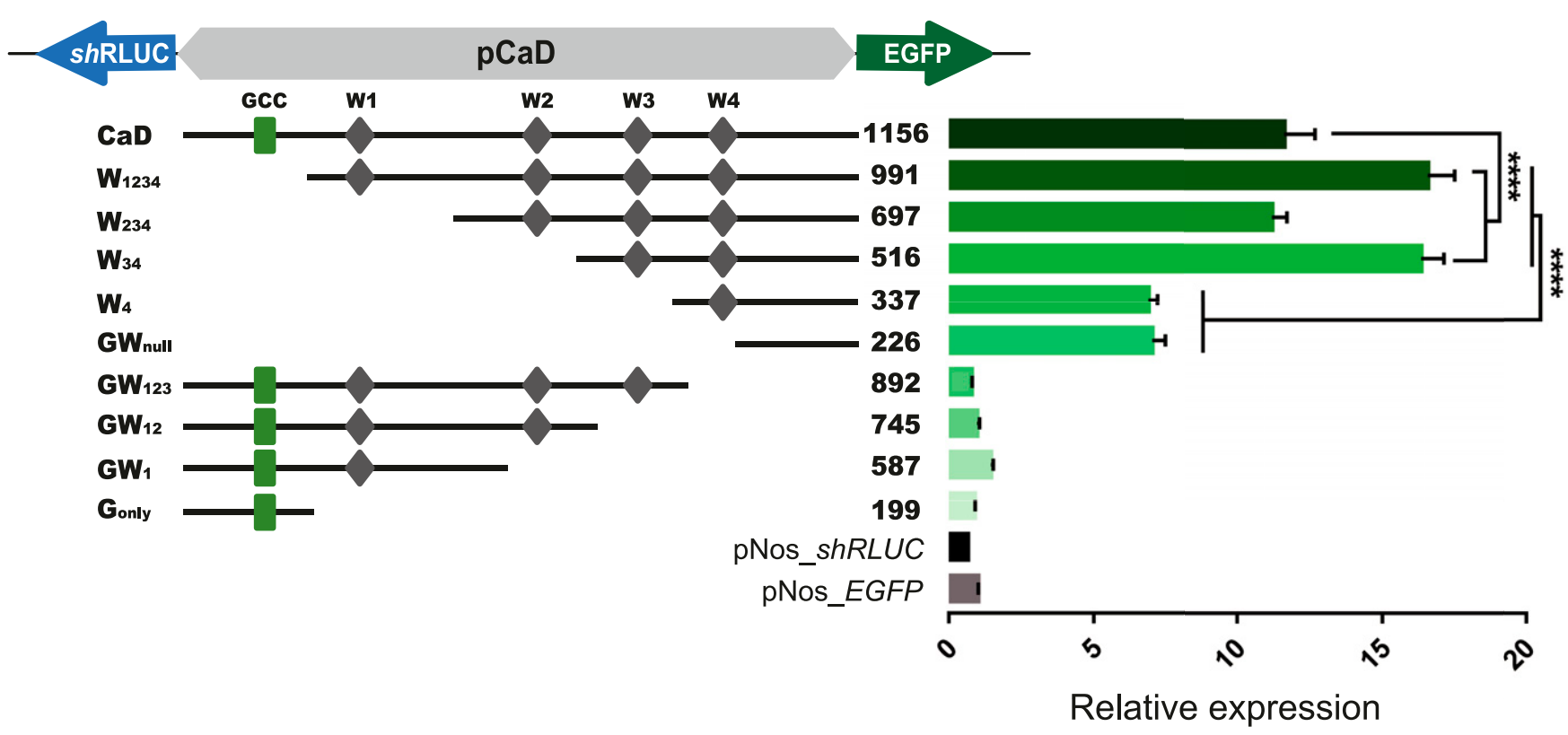

Fig. 2. Relative expression of enhanced green fluorescent protein (EGFP) according to the nested deletion of pCaD. EGFP driven by deletion promoters was transiently expressed in Nicotiana benthamiana via agroinfiltration. Fluorescence intensity was normalized by the expression of pNos_EGFP. $n=72$, error bar, \pm standard error of the mean. One-way analysis of variance and Dunn's multiple comparisons test was performed to compare expression driven by series of promoters. Asterisks (****) indicate $P<0.0001$

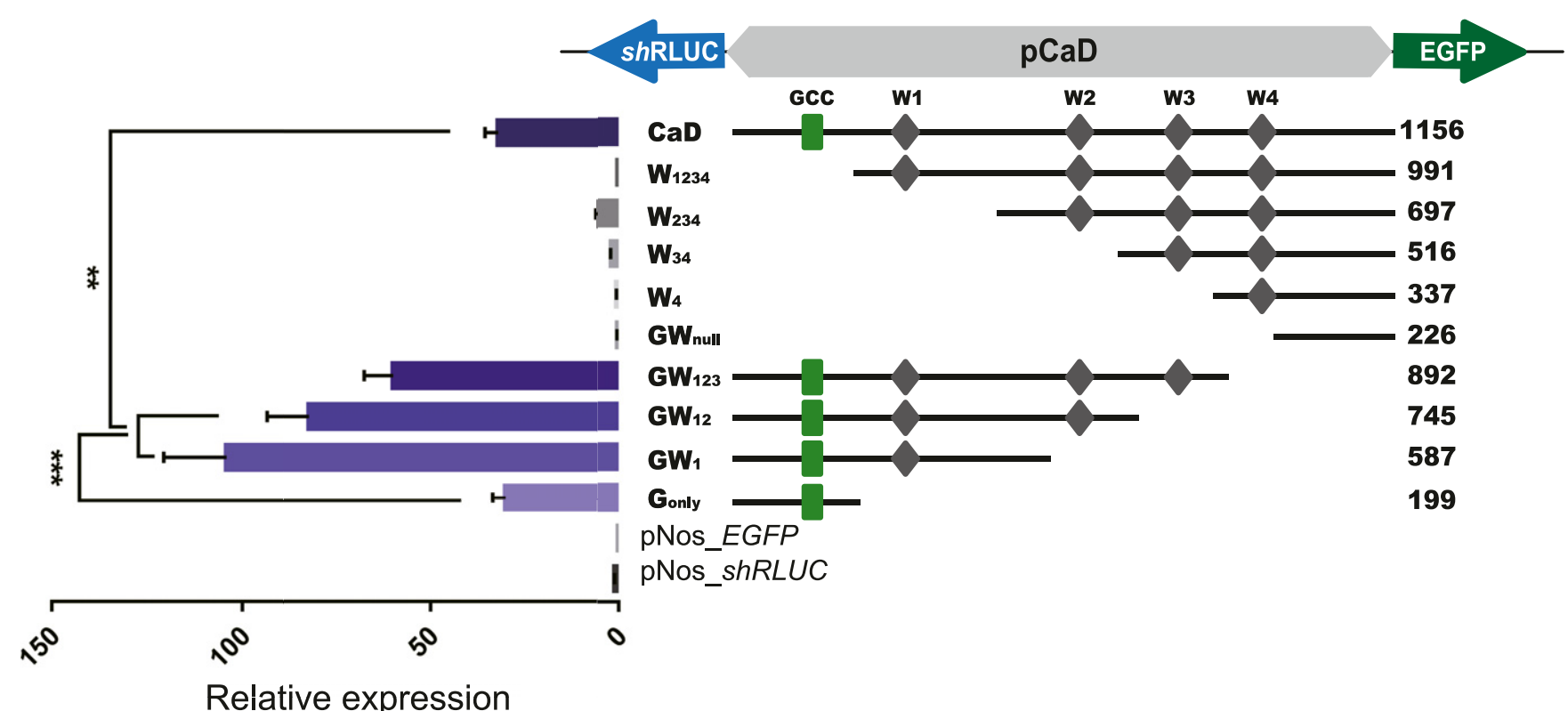

Fig. 3. Relative expression of shRLUC following removal of cis-acting elements in pCaD. Luminescence driven by a series of deletion promoters was measured after coelenterazine treatment. Final coelenterazine concentration was adjusted to $2 \mu \mathrm{M}$ in each well. shRLUC activity was normalized by the value of pNos_shRLUC. Error bar, \pm standard error of the mean, $n=72$. One-way analysis of variance and Dunn's multiple comparisons test was performed to compare expression driven by deletion promoters. Three asterisks $(* * *)$ indicate $P<0.001$, two $(* *) P<0.01$. 


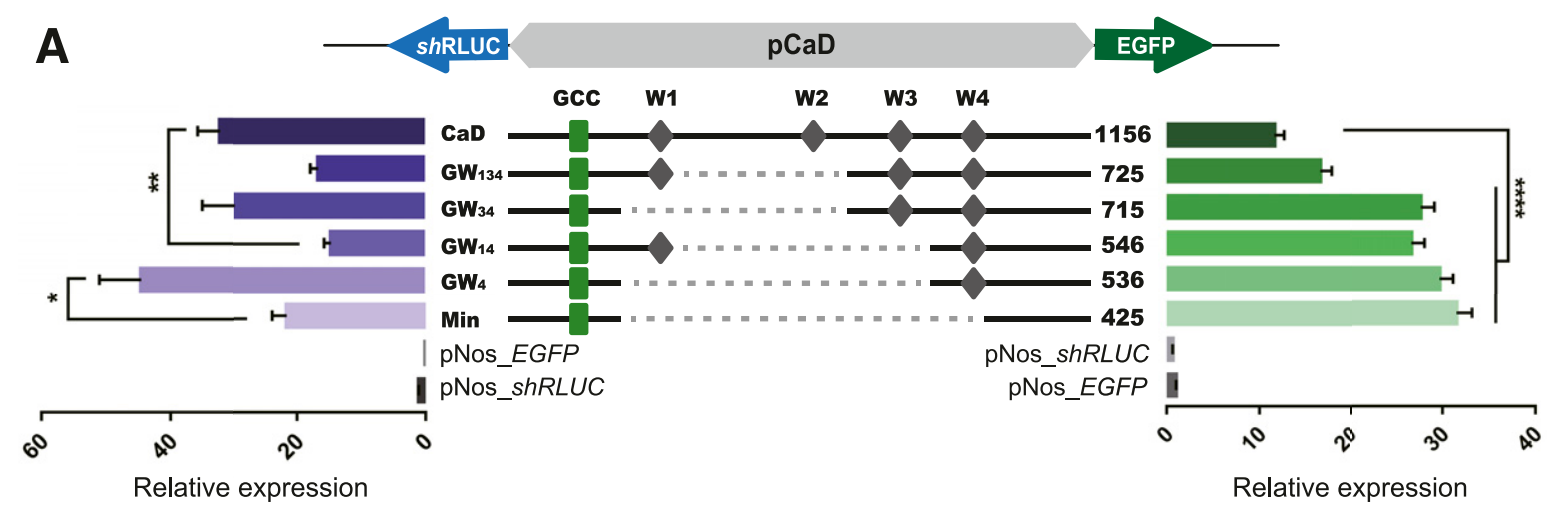

B

P. capsici

EGFP

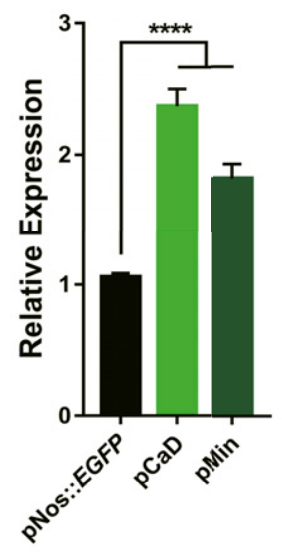

D Pst DC3000

EGFP

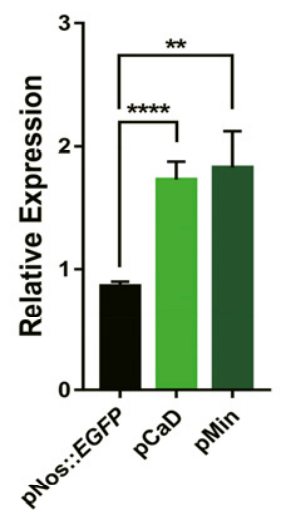

shRLUC

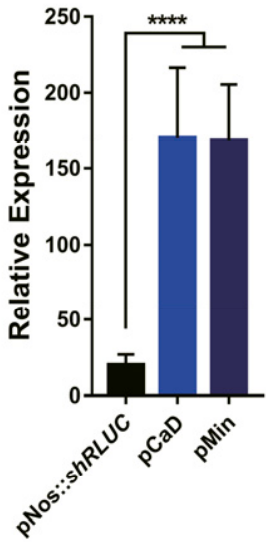

shRLUC

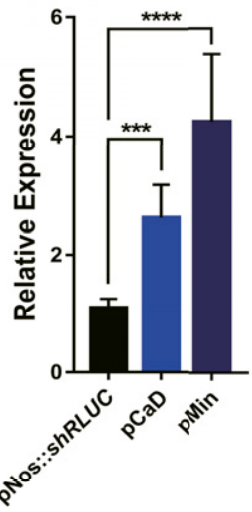

C P. infestans

EGFP

shRLUC
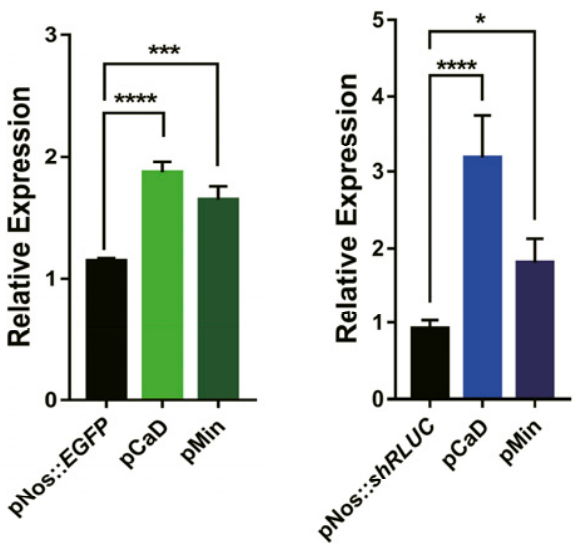

E B. cinerea

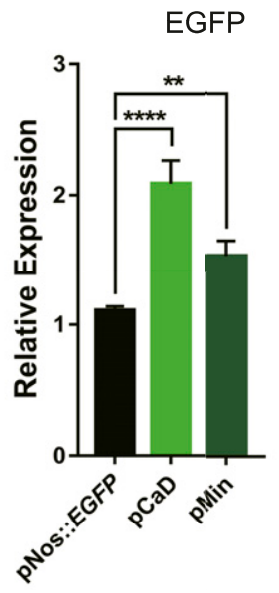

shRLUC

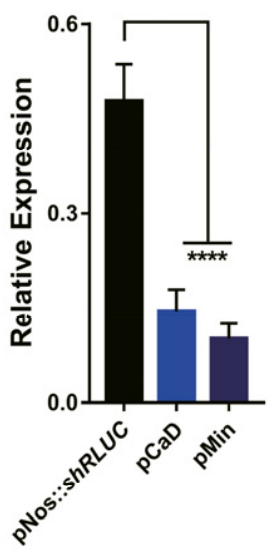

Fig. 4. Minimal synthetic promoter (pMin) drive enhanced reporter gene expression after Phytophthora capsici, P. infestans, Pseudomonas syringae pv. tomato DC3000 (Pst) but not Botrytis cinerea inoculation. A, Enhanced green fluorescent protein (EGFP) and shRLUC activity driven by a series of synthetic promoters. Reporter gene expressions were normalized EGFP and shRLUC driven by the Nos promoter. One-way analysis of variance and Dunn's multiple comparisons test was performed to compare expression driven by each synthetic promoter and pCaD. Four asterisks ( $* * * *)$ indicate $P<0.0001$, two $(* *) P<$ 0.01 , and one $\left.{ }^{*}\right) P<0.05$. B to E, Reporter gene expressions driven by $\mathrm{pCaD}$ and $\mathrm{pMin}$ change after $P$. capsici, P. infestans, Pseudomonas syringae pv. tomato DC3000, and B. cinerea. All relative expression was presented as fold changes based on mock-treated samples. Green and dark green bars mean EGFP fluorescence driven by $\mathrm{pCaD}$ and $\mathrm{pMin}$. Blue and dark blue bars represent shRLUC activities driven by $\mathrm{pCaD}$ and $\mathrm{pMin}$. A significant difference was detected using the Mann-Whitney test $(P<0.05)$. B, EGFP expression was measured at $12 \mathrm{~h}$ postinoculation (hpi). Error bar, \pm standard error of the mean $(\mathrm{SEM}), n=64$. shRLUC activity was measured at $24 \mathrm{hpi}$. Error bar, \pm SEM, $n=40$. C, EGFP expression was measured at $12 \mathrm{hpi}$. Error bar, \pm SEM, $n=64$. shRLUC activity was measured at 24 hpi. Error bar, \pm SEM, $n=24$. D, EGFP expression was measured at 12 hpi. Error bar, \pm SEM, $n=24$. shRLUC activity was measured at 12 hpi. Error bar, \pm SEM, $n=24$. E, EGFP expression was measured at 24 hpi, Error bar, \pm SEM, $n=64$. shRLUC activity was measured at 6 hpi. Error bar, \pm SEM, $n=40$. 
areas (Fig. 5C). In addition, a relatively decreased $F v / F m$ ratio was detected in pCaDrev::Pvr4-CC and pMinrev::Pvr4-CC expressed areas (Fig. 5D). These results indicate that the $\mathrm{pCaD}$ and the pMin promoter could bidirectionally drive the transcription of the cell death-inducing Pvr4-CC and elicit plant cell death successfully.

\section{DISCUSSION}

Phytoalexins contribute to plant defense against pathogens (Kuc 1995; Li et al. 2015; Lee et al. 2017; Park et al. 2014; Piasecka et al. 2015). Capsidiol, the phytoalexin in Nicotiana and Capsicum species, is de novo synthesized by pathogen

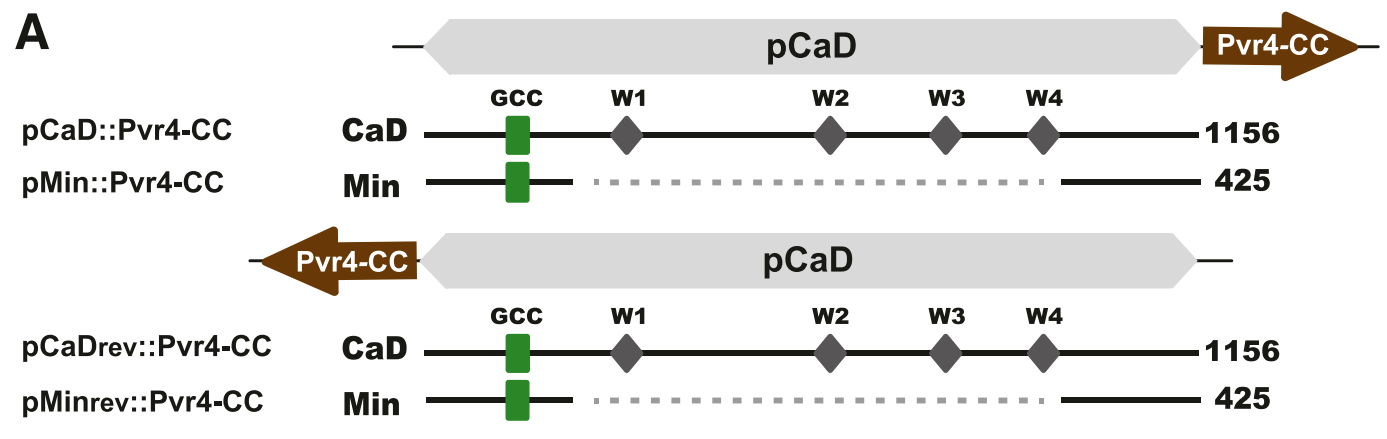

B
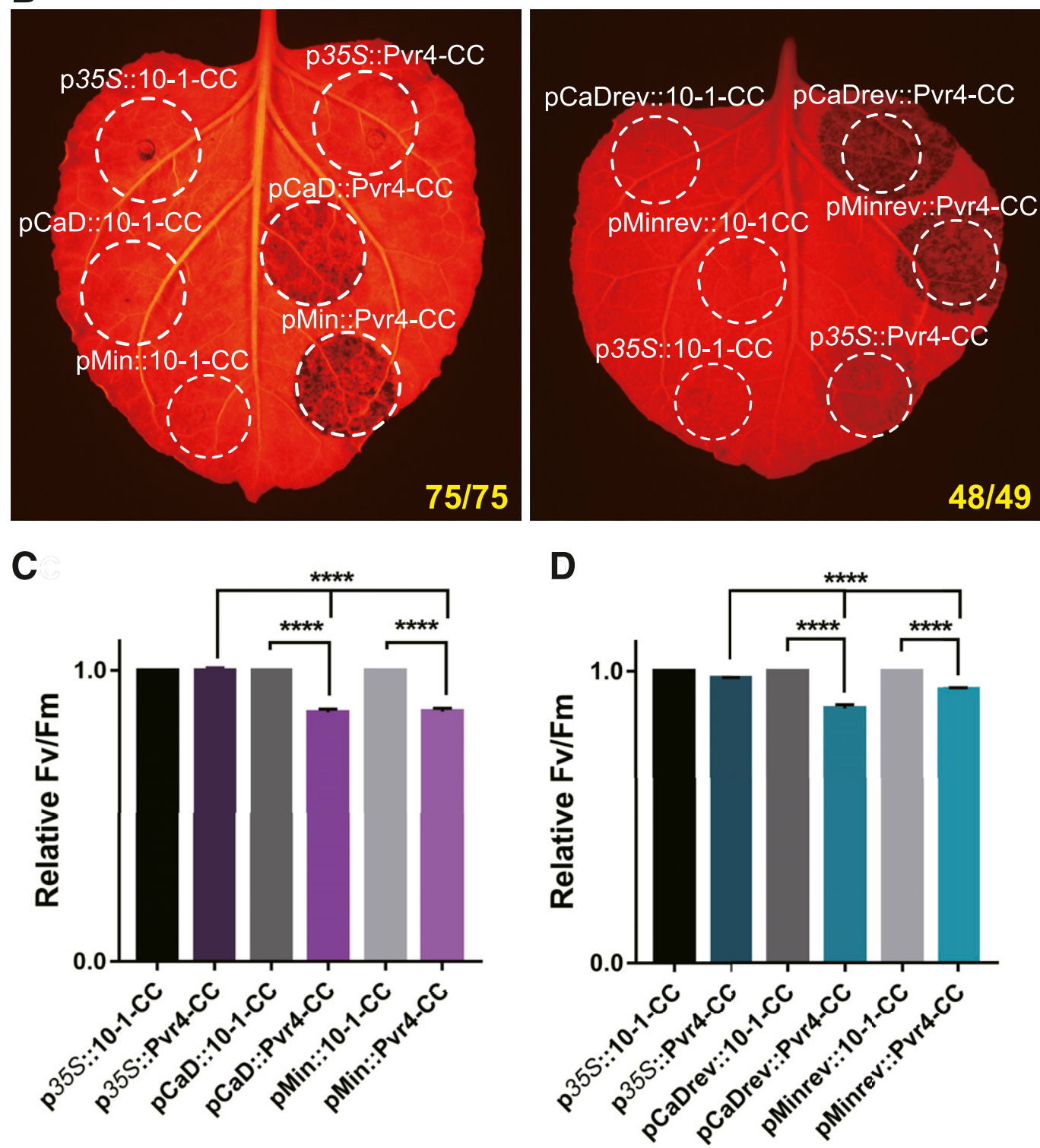

Fig. 5. Pvr4-CC expressions driven by $\mathrm{pCaD}$ and $\mathrm{pMin}$ elicit more substantial cell death than that of $35 \mathrm{~S}$ promoter. A, Scheme of Pvr4-CC and $\mathrm{pCaD}$ or $\mathrm{pMin}$ fusion construct. Pvr4-CC was fused to $\mathrm{pCaD}$ and $\mathrm{pMin}$ both directions to test whether $\mathrm{pCaD}$ and $\mathrm{pMin}$ elicit cell death. $\mathbf{B}$, Pvr4-CC and $\mathrm{pCaD}$ or pMin construct induced cell death in Nicotiana benthamiana. As a negative control, 10-1-CC fused to $\mathrm{pCaD}$ and $\mathrm{pMin}$ was used. A total of 75 and $49 \mathrm{~N}$. benthamiana leaves were used for infiltration of each construct, and 75 and 48 leaves showed the same results as presented. $\mathbf{C}$ and $\mathbf{D}, F v / F m$ value measurement after expression of each construct. Cell death intensity was normalized by the 10-1-CC expressed area. Significance of difference was detected using the Mann-Whitney test. Asterisks $(* * * *)$ indicate $P<0.05$. 
attack (Lee et al. 2017; Park et al. 2014; Stoessl et al. 1972). It is of interest that head-to-head orientation of capsidiol biosynthetic genes is a common configuration in the hot pepper genome because capsidiol biosynthetic genes $E A S$ and $E A H$ appear to be regulated simultaneously by a putative bidirectional promoter in response to biotic stimuli. In this study, we characterized a putative bidirectional promoter of capsidiol biosynthetic genes, named as $\mathrm{pCaD}$, and created a synthetic promoter, pMin, by measuring the expression of two reporter genes, shRLUC and EGFP, after the inoculation of four different pathogens. We confirmed that $\mathrm{pCaD}$ and $\mathrm{pMin}$ have sustained the inducible properties following pathogen infection. Our results suggested that $\mathrm{pCaD}$ and a synthetic minimal promoter pMin have the potential for making an inducible expression system for plant biotech, such as developing disease-resistant crops using a gene of interest (Fig. 4B, C, D, and $\mathrm{E})$.

The essential region of $\mathrm{pCaD}$ promoters was determined by deletion analyses (Figs. 2 and 3). Downstream region of the fourth W-box (W4) and GCC-box were critical for pathogeninduced gene expression in each direction. Especially in the case of $\mathrm{pG}_{\text {only }}$, shRLUC activity driven by $\mathrm{pG}_{\text {only }}$ and $\mathrm{pCaDrev}$ showed similar intensity, even if it is composed of only $199 \mathrm{bp}$ containing a GCC-box (Fig. 3). It is indicated that putative transcriptional factors, especially ERF, might be a major factor to control the adjacent gene expression. It is notable that treatment of the ethephon, an ethylene analog, also elevates the expression of CA02g09520 (EAS) and CA02g09530 (EAH) in C. annuum 'CM334' (Supplementary Fig. S3). These results imply that ethylene or ethylene-related factors might be involved in capsidiol biosynthesis in $C$. annuum 'CM334' and the activation of $C A 02 g 09520(E A S)$ and $C A 02 g 09530(E A H)$ en route to the capsidiol biosynthesis in $C$. annuum 'CM334'.

Based on the promoter deletion and recombination analysis, we generated a synthetic promoter set to maximize gene expressions in both directions. In Figure 4A, shRLUC activity was differentiated depending on the number of the W-box cis elements, while EGFP expression was elevated by the loss of the W-boxes. These results suggest that several WRKY transcription factors that bind to $\mathrm{W}$-box elements in $\mathrm{pCaD}$ might well coordinate the pathogen-inducible and bidirectional properties of the $\mathrm{pCaD}$ promoter.

The results from inoculations of various pathogens concluded that expressions of both reporter genes under $\mathrm{pCaD}$ and minimal promoter pMin showed enhanced expression of the reporter genes following the inoculation of bacterial pathogen Pseudomonas syringae pv. tomato DC3000 as well as two oomycete pathogens, $P$. capsici and $P$. infestans (Fig. 4B, C, and D). Interestingly, increased EGFP expression induced by B. cinerea was observed at $24 \mathrm{hpi}$, whereas the other tested pathogens induce enhanced EGFP expression at 12 hpi (Fig. 4B, C, D, and E). As shown in Supplementary Fig. S2, the accumulation of CA02g09520 (EAS) and CA02g09530 (EAH) transcripts were also delayed following the inoculation of $B$. cinerea in $C$. annuum 'CM334' compared with the inoculation of the bacterial pathogen Pseudomonas syringae pv. tomato DC3000 (Supplementary Fig. S2). Considering the different responsiveness of the $\mathrm{pCaD}$ promoter to a necrotic fungal pathogen, $B$. cinerea, it may imply that the capsidiol biosynthetic pathway can respond differentially to the infection of necrotrophic pathogens. In fact, the previous study revealed that $B$. cinerea could detoxify capsidiol by converting to capsenone (Ward and Stoessl 1972), suggesting that B. cinerea may also have developed a distinctive strategy to overcome the toxicity of capsidiol.

Auto-death of host cells by an immediate response to pathogen invasion is an excellent strategy to prevent successful colonization of pathogens. To test the feasibility of $\mathrm{pCaD}$ as a resource for making crops resistant against pathogens, the coiled-coil domain of Pvr4 (Pvr4-CC) was used as a proof of concept. $P v r 4$ was identified as a resistance gene against pepper mottle virus, pepper severe mosaic virus, and potato virus $\mathrm{Y}$ (Kim et al. 2017). The recognition of an avirulence factor, NIb, an RNA-dependent RNA polymerase of Potyviruses, by Pvr4 induces cell death (Kim et al. 2015). Recently, it has been shown that the expression of the Pvr4-CC domain under the cauliflower mosaic virus (CaMV) $35 S$ promoter is sufficient to induce cell death without NIb (Kim et al. 2018). To investigate whether Pvr4-CC can induce cell death under the control of $\mathrm{pCaD}$ and pMin, Pvr4-CC without its 5' UTR was linked to the promoters and was expressed in $N$. benthamiana. Interestingly, Pvr4-CC-mediated cell death under the control of $\mathrm{pCaD}$ and pMin was stronger than that driven by the CaMV $35 S$ promoter (Fig. 5B) by transient expression using Agrobacterium tumefaciens without any challenge pathogen, suggesting that Agrobacterium itself could induce the expression of Pvr4-CC, triggering the cell death as a pathogen. Moreover, lower values of the relative $F v / F m$ were detected in the Pvr4-CC expressed area driven by $\mathrm{pCaD}$ and pMin, confirming the Pvr4-CCmediated cell death (Fig. 5C and D). Because cell death driven by $\mathrm{pCaD}$ and $\mathrm{pMin}$ is induced by $A$. tumefaciens, perhaps it is challenging to make transgenic plants via agrobacteriummediated gene transfer. However, as shown in Supplementary Figure S3, CA02g09520 (EAS) and CA02g09530 (EAH) were not induced by wound stress, suggesting that gene transfer using particle bombardment would be an alternative way to produce a transgenic crop expressing the acute auto-cell death cassettes induced by pathogen invasion in the field (Supplementary Fig. S3). Taken together, the newly identified pCaD and synthetic pMin promoters could serve as powerful tools as bidirectional pathogen-inducible promoters for developing disease resistant crops against multiple pathogens including bacterial, oomycete, and filamentous fungal pathogens.

\section{MATERIALS AND METHODS}

\section{Plant materials and growth conditions.}

Nicotiana benthamiana was used for in planta expression. $N$. benthamiana seeds were germinated on the soil in controlled chambers with a 16 -h light and 8 -h dark photoperiod at $24^{\circ} \mathrm{C}$. Ten days after germination, seedlings were transplanted to a pot (100 $\mathrm{mm}$ diameter). Capsicum annuum cultivar Criollo de Morelos-334 ('CM334') was used for cloning the intergenic region of $C A 02 g 09520$ and $C A 02 g 0953$. Pepper seeds were germinated at $30^{\circ} \mathrm{C}$ in a dark incubator after sterilization with $0.2 \%$ sodium hypochlorite for 3 days. Pepper plants were transplanted to the 200-plug tray and were grown in a chamber with a 16 -h light and 8 -h dark photoperiod at $24^{\circ} \mathrm{C}$. Young pepper plants were transplanted to a 50-plug tray after cotyledon expansion.

\section{Cloning strategy.}

In $C$. annuum 'CM334', there are 29 EAS orthologs and 28 $E A H$ orthologs (Lee et al. 2017). Among a subset of $E A S$ and $E A H, C A 02 g 09520$ and $C A 02 g 09530$ were most highly expressed after $P$. infestans inoculation in CM334 (Lee et al. 2017). The intergenic region (1,156 bp) of CA02g09520 (EAS) and $C A 02 g 09530(E A H)$ was chosen as a putative pathogeninducible promoter. Specific primers to amplify the region of $\mathrm{pCaD}$ were designed based on the v1.55 reference genome of pepper (Kim et al. 2014). To make a series of the chimeric cassette of promoters, deleted $\mathrm{pCaD}$ promoters were produced by PCR amplification. Promoter deletions were conducted to remove cis elements, including a GCC-box and four W-box 
sequences in both directions. For generating a dual reporter cassette with deleted promoters, shRLUC (Woo et al. 2008) and EGFP genes were cloned in pCAMBIA2300 (pC2300) vector using KpnI, HindIII, PstI, and BamHI (New England Biolabs, Ipswich, MA, U.S.A.). T4 ligases (New England Biolabs) were used for ligation of a series of promoters, except $\mathrm{GW}_{12}$ and $\mathrm{G}_{\text {only }}$ promoters. EGFP and shRLUC genes were fused to the direction of $E A S$ transcription (pCaD::EGFP) and $E A H$ transcription (pCaDrev::shRLUC), respectively. $\mathrm{GW}_{12}$ and $\mathrm{G}_{\text {only }}$ were linked with shRLUC and EGFP by PCR and were cloned using ligation-independent cloning (Oh et al. 2010). shRLUC and EGFP under the Nos promoter were used as expression controls. The sequences of all clones were confirmed by DNA sequencing at the National Instrumentation Center for Environmental Management (NICEM, Seoul, Republic of Korea). Each cloned vector was transformed into A. tumefaciens GV3101 for in planta transient expression assays. Pvr4-CC constructs with $\mathrm{pCaD}$ and pMin were amplified by PCR and were cloned in the pC2300 vector. To test bidirectional inducibility, Pvr4-CC was fused with $\mathrm{pCaD}$ and $\mathrm{pMin}$ in both directions.

\section{In planta expression assay.}

After transformation to A. tumefaciens (GV3101) using heat shock, cells were cultured at $28^{\circ} \mathrm{C}$ in a shaking incubator for $12 \mathrm{~h}$. Cultured cells were centrifuged and resuspended by induction buffer $\left(10 \mathrm{mM}\right.$ MES, $\mathrm{pH} 5.6,10 \mathrm{mM} \mathrm{MgCl}_{2}$, and $150 \mu \mathrm{M}$ acetosyringone) and were incubated at $28^{\circ} \mathrm{C}$ for $2 \mathrm{~h}$ before agroinfiltration. The concentration of cells was adjusted to 0.3 at an optical density at $600 \mathrm{~nm}\left(\mathrm{OD}_{600}\right)$ for expression in $N$. benthamiana and were pressure-infiltrated using needleless syringes (Sparkes et al. 2006). After agroinfiltration, plants were stored in a controlled chamber with a 16-h light and 8-h dark photoperiod at $24^{\circ} \mathrm{C}$ for measuring expression of reporter genes or $21^{\circ} \mathrm{C}$ for the pathogen inoculation test.

\section{Measurement of cell death intensity.}

To measure cell death induced by $\mathrm{pCaD}$ and pMin with Pvr4$\mathrm{CC}$, constructs of Pvr4-CC-fused $\mathrm{pCaD}$ and pMin were transiently expressed in $N$. benthamiana via agroinfiltration. Two days after infiltration, detached $N$. benthamiana leaves were used to validate the inducible property of $\mathrm{pCaD}$ and pMin. 10$1-\mathrm{CC}$ fused to $35 \mathrm{~S}$ promoter, $\mathrm{pCaD}$, and $\mathrm{pMin}$ were used as negative controls of Pvr4-CC driven by $35 \mathrm{~S}$, pCaD, or pMin. Cell death intensity was measured using FluorCAM (Photon System Instruments, Drasov, Czech) and the value of $F v / F m$ was presented as an indicator of cell death intensity.

\section{Fluorescence and luminescence expression assay.}

To detect green fluorescence and luminescence derived by promoters, leaf discs were sampled after transient expression, using a cork borer (diameter $=4 \mathrm{~mm}$ ). Sampled leaf discs were floated in black 96-well plates with $100 \mu$ l of distilled water. EGFP and shRLUC expression induced by agrobacterium was measured 2 days after infiltration. EGFP fluorescence and luminescence from shRLUC with coelenterazine (native) (Biotium, Fremont, CA, U.S.A.) was measured using a Synergy HTX plate reader (Biotek, Winooski, VT, U.S.A.). Coelenterazine concentration was adjusted to $2 \mu \mathrm{M}$ in each well. To measure fluorescence and luminescence changed by pathogens, leaf discs from agroinfiltrated $N$. benthamiana leaves were sampled using a cork borer at $24 \mathrm{~h}$ after agroinfiltration, followed by the addition of pathogen suspensions to the 96-well plates. The expression of reporter genes was measured at 0,6 , 12 and 24 hpi. Change of gene expression was normalized with the expression of mock-treated samples.

\section{Pathogen inoculation.}

Two Phytophthora species, the potato late blight pathogen $P$. infestans and $P$. capsici were used. $P$. capsici (40476) was grown on V8 media at room temperature in the dark for 5 days. The mycelia were scraped using a spreader and were incubated under white light for $12 \mathrm{~h}$. Dried mycelia were flooded with $5 \mathrm{ml}$ of distilled water and were incubated on ice for releasing zoospores from sporangia. Zoospores were adjusted to $5 \times 10^{4}$ spores per milliliter for inoculation. P. infestans (T30-4) was grown on rye agar media at $17^{\circ} \mathrm{C}$ in dark conditions for 1 days. Zoospores were captured by flooding the plate with $7 \mathrm{ml}$ of sterile distilled water and were incubated at $4{ }^{\circ} \mathrm{C}$ until released from sporangia. The released zoospore was adjusted to $10 \times 10^{4}$ spores per milliliter using distilled water for inoculation. The bacterial pathogen Pseudomonas syringae pv. tomato DC3000 without HopQ1 effector (Wei et al. 2007) was grown in King's B media with proper antibiotics. The cultured cell was centrifuged and resuspended by buffer $(10 \mathrm{mM} \mathrm{MgCl} 2)$ and was adjusted to 0.01 at $\mathrm{OD}_{600}$. Necrotrophic fungi Botrytis cinerea isolate 05.10 was grown on potato dextrose agar media without antibiotics, for about 3 weeks, at room temperature in dark conditions. Gently rubbed mycelia with autoclaved distilled water was filtered by Mira cloths to harvest the conidiospores. Captured spores were diluted with $25 \%$ organic grape juice and were adjusted to $1 \times$ $10^{5}$ spores per milliliter for inoculation.

\section{Quantitative reverse transcription (qRT)-PCR analysis.}

To investigate whether CA02g09520 (EAS) and CA02g09530 $(E A H)$ are activated after wound and ethylene treatment, CM334 was treated with the ethylene analog ethephon (ET) and with wounding stress. Ethephon solutions $(25 \mathrm{ml})$ were sprayed on 5-week-old pepper leaves. Water with $0.01 \%$ Tween 20 was prepared as a spraying buffer and $10 \%$ ethanol with buffer was used as a mock. Wounds were given to pepper leaves using needles. Five leaves were detached at each timepoint and whole leaves were ground with liquid nitrogen, using a glazed porcelain mortar with pestle. To confirm CA02g09520 (EAS) and CA02g09530 (EAH) are induced by Pseudomonas syringae pv. tomato DC3000 and B. cinerea infection, 5-week-old pepper leaves were used. Pathogen preparation was conducted the same as mentioned above. Five leaf discs were used for RNA extraction.

Total RNA was extracted from finely ground powders, using the TRIZOL method according to the manufacturer instructions (Invitrogen, Carlsbad, CA, U.S.A.). First-strand cDNA was synthesized using $2 \mu \mathrm{g}$ of total RNAs with oligo (dT) and the Superscript II RT (Invitrogen) for qRT-PCR analysis. qRT-PCR was conducted using $25 \mathrm{ng}$ of cDNA per microliter with premix from Applied Biosystems (Applied Biosystems, Foster city, CA, U.S.A.). To determine relative expression of $C A 02 g 09520$ $(E A S)$ and $C A 02 g 09530(E A H)$ in each sample, specific primers were used (Supplementary Table 1). To normalize the expression level, the pepper ACTIN gene was used as an endogenous control.

\section{Statistical analyses.}

Statistical analysis and graphs were generated by Prism (Graphpad, San Diego, CA, U.S.A.) software. One-way analysis of variance and Dunn's multiple comparisons test was performed to compare expression driven by series of promoters. A Mann-Whitney test was performed to analyze variance between expressions induced by agroinfiltration and inoculation of four different pathogens.

\section{ACKNOWLEDGMENT}

A patent application based on this work is pending with the Korean Government (10-2020-0034930). 


\section{LITERATURE CITED}

Adachi, H., Nakano, T., Miyagawa, N., Ishihama, N., Yoshioka, M., Katou, Y., Yaeno, T., Shirasu, K., and Yoshioka, H. 2015. WRKY transcription factors phosphorylated by MAPK regulate a plant immune NADPH oxidase in Nicotiana benthamiana. Plant Cell 27:2645-2663.

Alexander, D., Goodman, R. M., Gut-Rella, M., Glascock, C., Weymann, K., Friedrich, L., Maddox, D., Ahl-Goy, P., Luntz, T., and Ward, E. 1993. Increased tolerance to two oomycete pathogens in transgenic tobacco expressing pathogenesis-related protein 1a. Proc. Natl. Acad. Sci. U.S.A. 90:7327-7331.

Arnaiz, A., Martinez, M., Gonzalez-Melendi, P., Grbic, V., Diaz, I., and Santamaria, M. E. 2019. Plant defenses against pests driven by a bidirectional promoter. Front. Plant Sci. 10:930.

Baćmaga, M., Wyszkowska, J., and Kucharski, J. 2016. The effect of the Falcon 460 EC fungicide on soil microbial communities, enzyme activities and plant growth. Ecotoxicology 25:1575-1587.

Bailey, J. A., Vincent, G. G., and Burden, R. S. 1976. The antifungal activity of glutinosone and capsidiol and their accumulation in virus-infected tobacco species. Physiol. Plant Pathol. 8:35-41.

Bednarek, P., Piślewska-Bednarek, M., Ver Loren van Themaat, E., Maddula, R. K., Svatoš, A., and Schulze-Lefert, P. 2011. Conservation and clade-specific diversification of pathogen-inducible tryptophan and indole glucosinolate metabolism in Arabidopsis thaliana relatives. New Phytol. 192:713-726.

Boller, T., and Felix, G. 2009. A renaissance of elicitors: Perception of microbe-associated molecular patterns and danger signals by patternrecognition receptors. Annu. Rev. Plant Biol. 60:379-406.

Boni, R., Chauhan, H., Hensel, G., Roulin, A., Sucher, J., Kumlehn, J., Brunner, S., Krattinger, S. G., and Keller, B. 2018. Pathogen-inducible Ta-Lr34res expression in heterologous barley confers disease resistance without negative pleiotropic effects. Plant Biotechnol. J. 16 245-253.

Brogue, K., Chet, I., Holliday, M., Cressman, R., Biddle, P., Knowlton, S., Mauvais, C. J., and Broglie, R. 1991. Transgenic plants with enhanced resistance to the fungal pathogen Rhizoctonia solani. Science 254: 1194-1197.

Cao, H., Li, X., and Dong, X. 1998. Generation of broad-spectrum disease resistance by overexpression of an essential regulatory gene in systemic acquired resistance. Proc. Natl. Acad. Sci. U.S.A. 95:6531-6536.

Carvalho, F. P. 2017. Pesticides, environment, and food safety. Food Energy Secur. 6:48-60.

Chakraborty, S., and Newton, A. C. 2011. Climate change, plant diseases and food security: An overview. Plant Pathol. 60:2-14.

Chen, C., and Chen, Z. 2002. Potentiation of developmentally regulated plant defense response by AtWRKY18, a pathogen-induced Arabidopsis transcription factor. Plant Physiol. 129:706-716.

Choi, D., Bostock, R. M., Avdiushko, S., and Hildebrand, D. F. 1994. Lipidderived signals that discriminate wound- and pathogen-responsive isoprenoid pathways in plants: Methyl jasmonate and the fungal elicitor arachidonic acid induce different 3-hydroxy-3-methylglutaryl-coenzyme A reductase genes and antimicrobial isoprenoids in Solanum tuberosum L. Proc. Natl. Acad. Sci. U.S.A. 91:2329-2333.

Choi, D., Ward, B. L., and Bostock, R. M. 1992. Differential induction and suppression of potato 3-hydroxy-3-methylglutaryl coenzyme A reductase genes in response to Phytophthora infestans and to its elicitor arachidonic acid. Plant Cell 4:1333-1344.

Eulgem, T., Rushton, P. J., Robatzek, S., and Somssich, I. E. 2000. The WRKY superfamily of plant transcription factors. Trends Plant Sci. 5: 199-206.

Ficke, A., Cowger, C., Bergstrom, G., and Brodal, G. 2018. Understanding yield loss and pathogen biology to improve disease management: Septoria nodorum blotch-A case study in wheat. Plant Dis. 102: 696-707.

Fitzgerald, H. A., Chern, M. S., Navarre, R., and Ronald, P. C. 2004 Overexpression of (At)NPRI in rice leads to a BTH- and environmentinduced lesion-mimic/cell death phenotype. Mol. Plant-Microbe Interact. 17:140-151.

Fujimoto, S. Y., Ohta, M., Usui, A., Shinshi, H., and Ohme-Takagi, M. 2000. Arabidopsis ethylene-responsive element binding factors act as transcriptional activators or repressors of GCC box-mediated gene expression. Plant Cell 12:393-404.

Giannakopoulou, A., Schornack, S., Bozkurt, T. O., Haart, D., Ro, D. K., Faraldos, J. A., Kamoun, S., and O'Maille, P. E. 2014. Variation in capsidiol sensitivity between Phytophthora infestans and Phytophthora capsici is consistent with their host range. PLoS One 9:e107462.

Gust, A. A., Biswas, R., Lenz, H. D., Rauhut, T., Ranf, S., Kemmerling, B., Götz, F., Glawischnig, E., Lee, J., Felix, G., and Nürnberger, T. 2007.
Bacteria-derived peptidoglycans constitute pathogen-associated molecular patterns triggering innate immunity in Arabidopsis. J. Biol. Chem. 282:32338-32348.

Ham, J. H., Kim, M. G., Lee, S. Y., and Mackey, D. 2007. Layered basal defenses underlie non-host resistance of Arabidopsis to Pseudomonas syringae pv. phaseolicola. Plant J. 51:604-616.

Heath, M. C. 2000. Nonhost resistance and nonspecific plant defenses. Curr. Opin. Plant Biol. 3:315-319.

Jin, J. H., Zhang, H. X., Tan, J. Y., Yan, M. J., Li, D. W., Khan, A., and Gong, Z. H. 2016. A new ethylene-responsive factor CaPTI1 gene of pepper (Capsicum annuиm L.) involved in the regulation of defense response to Phytophthora capsici. Front. Plant Sci. 6:1217.

Kamoun, S., Huitema, E., and Vleeshouwers, V. G. 1999. Resistance to oomycetes: A general role for the hypersensitive response? Trends Plant Sci. 4:196-200.

Keller, H., Pamboukdjian, N., Ponchet, M., Poupet, A., Delon, R., Verrier, J. L., Roby, D., and Ricci, P. 1999. Pathogen-induced elicitin production in transgenic tobacco generates a hypersensitive response and nonspecific disease resistance. Plant Cell 11:223-235.

Kim, S., Park, M., Yeom, S. I., Kim, Y. M., Lee, J. M., Lee, H. A., Seo, E., Choi, J., Cheong, K., Kim, K. T., Jung, K., Lee, G. W., Oh, S. K., Bae, C., Kim, S. B., Lee, H. Y., Kim, S. Y., Kim, M. S., Kang, B. C., Jo, Y. D., Yang, H. B., Jeong, H. J., Kang, W. H., Kwon, J. K., Shin, C., Lim, J. Y., Park, J. H., Huh, J. H., Kim, J. S., Kim, B. D., Cohen, O., Paran, I., Suh, M. C., Lee, S. B., Kim, Y. K., Shin, Y., Noh, S. J., Park, J., Seo, Y. S., Kwon, S. Y., Kim, H. A., Park, J. M., Kim, H. J., Choi, S. B., Bosland, P. W., Reeves, G., Jo, S. H., Lee, B. W., Cho, H. T., Choi, H. S., Lee, M. S., Yu, Y., Do Choi, Y., Park, B. S., van Deynze, A., Ashrafi, H., Hill, T., Kim, W. T., Pai, H. S., Ahn, H. K., Yeam, I., Giovannoni, J. J., Rose, J. K., Sørensen, I., Lee, S. J., Kim, R. W., Choi, I. Y., Choi, B. S., Lim, J. S., Lee, Y. H., and Choi, D. 2014. Genome sequence of the hot pepper provides insights into the evolution of pungency in Capsicum species. Nat. Genet. 46:270-278.

Kim, S. B., Kang, W. H., Huy, H. N., Yeom, S. I., An, J. T., Kim, S., Kang, M. Y., Kim, H. J., Jo, Y. D., Ha, Y., Choi, D., and Kang, B. C. 2017. Divergent evolution of multiple virus-resistance genes from a progenitor in Capsicum spp. New Phytol. 213:886-899.

Kim, S. B., Lee, H. Y., Choi, E. H., Park, E., Kim, J. H., Moon, K. B., Kim, H. S., and Choi, D. 2018. The coiled-coil and leucine-rich repeat domain of the potyvirus resistance protein Pvr4 has a distinct role in signaling and pathogen recognition. Mol. Plant-Microbe Interact. 31:906-913.

Kim, S. B., Lee, H. Y., Seo, S., Lee, J. H., and Choi, D. 2015. RNAdependent RNA polymerase (NIb) of the potyviruses is an avirulence factor for the broad-spectrum resistance gene Pvr4 in Capsicum annuum cv. CM334. PLoS One 10:e0119639.

Kuc, J. 1995. Phytoalexins, stress metabolism, and disease resistance in plants. Annu. Rev. Phytopathol. 33:275-297.

Lee, H. A., Kim, S., Kim, S., and Choi, D. 2017. Expansion of sesquiterpene biosynthetic gene clusters in pepper confers nonhost resistance to the Irish potato famine pathogen. New Phytol. 215: $1132-1143$.

Lee, H. Y., Mang, H., Choi, E. H., Seo, Y. E., Kim, M. S., Oh, S., Kim, S. B., and Choi, D. 2020. Genome-wide functional analysis of hot pepper immune receptors reveals an autonomous NLR cluster in seed plants. bioRxiv. Published online. 10.1101/2019.12.16.878959

Li, J., Brader, G., and Palva, E. T. 2004. The WRKY70 transcription factor: A node of convergence for jasmonate-mediated and salicylate-mediated signals in plant defense. Plant Cell 16:319-331.

Li, R., Tee, C. S., Jiang, Y. L., Jiang, X. Y., Venkatesh, P. N., Sarojam, R., and Ye, J. 2015. A terpenoid phytoalexin plays a role in basal defense of Nicotiana benthamiana against Potato virus X. Sci. Rep. 5:9682.

Lu, X., Zhang, L., Zhang, F., Jiang, W., Shen, Q., Zhang, L., Lv, Z., Wang, G., and Tang, K. 2013. AaORA, a trichome-specific AP2/ERF transcription factor of Artemisia аппиа, is a positive regulator in the artemisinin biosynthetic pathway and in disease resistance to Botrytis cinerea. New Phytol. 198:1191-1202.

Nalley, L., Tsiboe, F., Durand-Morat, A., Shew, A., and Thoma, G. 2016. Economic and environmental impact of rice blast pathogen (Magnaporthe oryzae) alleviation in the United States. PLoS One 11: $\mathrm{e} 0167295$.

Nürnberger, T., and Lipka, V. 2005. Non-host resistance in plants: New insights into an old phenomenon. Mol. Plant Pathol. 6:335-345.

Oh, S. K., Kim, S. B., Yeom, S. I., Lee, H. A., and Choi, D. 2010. Positiveselection and ligation-independent cloning vectors for large scale in planta expression for plant functional genomics. Mol. Cells 30:557-562.

Ohme-Takagi, M., and Shinshi, H. 1995. Ethylene-inducible DNA binding proteins that interact with an ethylene-responsive element. Plant Cell 7 : 173-182. 
Park, S., Park, A. R., Im, S., Han, Y. J., Lee, S., Back, K., Kim, J. I., and Kim, Y. S. 2014. Developmentally regulated sesquiterpene production confers resistance to Colletotrichum gloeosporioides in ripe pepper fruits. PLoS One 9:e109453.

Piasecka, A., Jedrzejczak-Rey, N., and Bednarek, P. 2015. Secondary metabolites in plant innate immunity: Conserved function of divergent chemicals. New Phytol. 206:948-964.

Ralston, L., Kwon, S. T., Schoenbeck, M., Ralston, J., Schenk, D. J., Coates, R. M., and Chappell, J. 2001. Cloning, heterologous expression, and functional characterization of 5-epi-aristolochene-1,3-dihydroxylase from tobacco (Nicotiana tabacum). Arch. Biochem. Biophys. 393: 222-235.

Robert-Seilaniantz, A., Navarro, L., Bari, R., and Jones, J. D. 2007. Pathological hormone imbalances. Curr. Opin. Plant Biol. 10:372-379.

Sarris, P. F., Duxbury, Z., Huh, S. U., Ma, Y., Segonzac, C., Sklenar, J., Derbyshire, P., Cevik, V., Rallapalli, G., Saucet, S. B., Wirthmueller, L., Menke, F. L. H., Sohn, K. H., and Jones, J. D. G. 2015. A plant immune receptor detects pathogen effectors that target WRKY transcription factors. Cell 161:1089-1100.

Seo, E., Choi, D., and Choi. 2015. Functional studies of transcription factors involved in plant defenses in the genomics era. Brief. Funct. Genomics 14:260-267.

Shin, R., Kim, M. J., and Paek, K. H. 2003. The CaTin1 (Capsicum annuum TMV-induced clone 1) and CaTin1-2 genes are linked head-to-head and share a bidirectional promoter. Plant Cell Physiol. 44:549-554.

Song, N., Ma, L., Wang, W., Sun, H., Wang, L., Baldwin, I. T., and Wu, J. 2019. An ERF2-like transcription factor regulates production of the defense sesquiterpene capsidiol upon Alternaria alternata infection. J. Exp. Bot. 70:5895-5908.

Sparkes, I. A., Runions, J., Kearns, A., and Hawes, C. 2006. Rapid, transient expression of fluorescent fusion proteins in tobacco plants and generation of stably transformed plants. Nat. Protoc. 1:2019-2025.

Starks, C. M., Back, K., Chappell, J., and Noel, J. P. 1997. Structural basis for cyclic terpene biosynthesis by tobacco 5-epi-aristolochene synthase. Science 277:1815-1820.

Stoessl, A., Unwin, C. H., and Ward, E. W. B. 1972. Postinfectional inhibitors from plants I. Capsidiol, an antifungal compound from Capsicum frutescens. Phytopathology 74:141-152.

Truong, H. T. H., Kim, K. T., Kim, D. W., Kim, S., Chae, Y., Park, J. H., Oh, D. G., and Cho, M. C. 2012. Identification of isolate-specific resistance QTLs to phytophthora root rot using an intraspecific recombinant inbred line population of pepper (Capsicum annuum). Plant Pathol. 61:48-56.

Ülker, B., and Somssich, I. E. 2004. WRKY transcription factors: From DNA binding towards biological function. Curr. Opin. Plant Biol. 7:491-498.
Vleeshouwers, V. G., van Dooijeweert, W., Govers, F., Kamoun, S., and Colon, L. T. 2000. The hypersensitive response is associated with host and nonhost resistance to Phytophthora infestans. Planta 210:853-864.

Vögeli, U., and Chappell, J. 1988. Induction of sesquiterpene cyclase and suppression of squalene synthetase activities in plant cell cultures treated with fungal elicitor. Plant Physiol. 88:1291-1296.

Ward, E. W. B., and Stoessl, A. 1972. Postinfectional inhibitors from plants III. Detoxification of capsidiol, an antifungal compound from Peppers. Phytopathology 62:1186-1187.

Wei, C. F., Kvitko, B. H., Shimizu, R., Crabill, E., Alfano, J. R., Lin, N. C., Martin, G. B., Huang, H. C., and Collmer, A. 2007. A Pseudomonas syringae pv. tomato DC3000 mutant lacking the type III effector HopQ11 is able to cause disease in the model plant Nicotiana benthamiana. Plant J. 51:32-46.

Whitehead, I. M., Threlfall, D. R., and Ewing, D. F. 1989. 5-epiaristolochene is a common precursor of the sesquiterpenoid phytoalexins capsidiol and debneyol. Phytochemistry 28:775-779.

Woo, J., Howell, M. H., and von Arnim, A. G. 2008. Structure-function studies on the active site of the coelenterazine-dependent luciferase from Renilla. Protein Sci. 17:725-735.

Wyszkowska, J., and Kucharski, J. 2004. Biochemical and physicochemical properties of soil contaminated with herbicide Triflurotox 250 EC. Pol. J. Environ. Stud. 13:223-231.

Xu, G., Yuan, M., Ai, C., Liu, L., Zhuang, E., Karapetyan, S., Wang, S., and Dong, X. 2017. uORF-mediated translation allows engineered plant disease resistance without fitness costs. Nature 545:491-494.

Yamamizo, C., Kuchimura, K., Kobayashi, A., Katou, S., Kawakita, K., Jones, J. D., Doke, N., and Yoshioka, H. 2006. Rewiring mitogenactivated protein kinase cascade by positive feedback confers potato blight resistance. Plant Physiol. 140:681-692.

Yang, C., Li, W., Cao, J., Meng, F., Yu, Y., Huang, J., Jiang, L., Liu, M., Zhang, Z., Chen, X., Miyamoto, K., Yamane, H., Zhang, J., Chen, S., and Liu, J. 2017. Activation of ethylene signaling pathways enhances disease resistance by regulating ROS and phytoalexin production in rice. Plant $\mathrm{J}$. 89:338-353.

Yi, H., and Richards, E. J. 2007. A cluster of disease resistance genes in Arabidopsis is coordinately regulated by transcriptional activation and RNA silencing. Plant Cell 19:2929-2939.

Zhao, B., Lin, X., Poland, J., Trick, H., Leach, J., and Hulbert, S. 2005. A maize resistance gene functions against bacterial streak disease in rice. Proc. Natl. Acad. Sci. U.S.A. 102:15383-15388.

Zhu, S., Li, Y., Vossen, J. H., Visser, R. G., and Jacobsen, E. 2012. Functional stacking of three resistance genes against Phytophthora infestans in potato. Transgenic Res. 21:89-99. 